\title{
ANALISIS TATA KELOLA KAPASITAS LAYANAN TEKNOLOGI INFORMASI PERUSAHAAN ASURANSI SOSIAL MENGGUNAKAN STANDAR ISO 20000:1-2018
}

\author{
Anggraeni Ridwan ${ }^{1}$, Agus Suwinto ${ }^{2}$ \\ Dosen Universitas Gunadarma ${ }^{1}$, Mahasiswa Universitas Gunadarma ${ }^{2}$ \\ Jalan Margonda Raya No.100 Pondok Cina, Depok, Jawa Barat \\ Sur-el : nenirid26@gmail.com ${ }^{1}$, agus.suwinto@gmail.com²
}

\begin{abstract}
Social insurance company has mission to protect all people, avoid the risk of social life, so social insurance company must provide public services that are easy to use. To provide fast, accurate, and information, ensuring the reliability of information technology service capacity governance is very important. Social insurance company needs period of preparation for development towards vision (Good Governance, Risk Management, and Compliance) in service excellence, taking into account the governance of information technology service capacity which is important factor for Social Insurance Company. ISO is a standard-setting body that provides world-class specifications for variety of things, from products, services and systems, to ensure quality, safety and efficiency. Therefore, this paper provides an overview the implementation of ISO 20000-1: 2018 standards for Information Technology Services Capacity Management with standardization clauses for social insurance company and review information technology service capacity governance standards as considerations and proposals to Social Insurance Company.
\end{abstract}

Keywords: Good governance, capacity, information technology, ISO 20000:1-2018.

\begin{abstract}
Abstrak : Perusahaan asuransi sosial mempunyai misi untuk melindungi semua masyarakat agar terhindar dari risiko kehidupan sosialnya, maka perusahaan asuransi sosial harus menyediakan pelayanan publik yang mudah digunakan. Untuk menyediakan informasi yang cepat, akurat, dan mudah, maka memastikan keandalan dalam tata kelola kapasitas layanan teknologi informasi menjadi hal yang sangat penting. Perusahaan asuransi sosial memerlukan masa persiapan pembangunan menuju visinya (Good Governance, Risk Management, and Compliance) dalam service excellence, dengan memperhatikan tata kelola kapasitas layanan teknologi informasi dimana menjadi faktor penting bagi Perusahaan Asuransi Sosial. ISO merupakan badan penetap standarisasi yang memberikan spesifikasi kelas dunia untuk berbagai hal, mulai dari produk, layanan, dan sistem, untuk memastikan kualitas, keamanan, dan efisiensi. Oleh karena itu, penelitian ini memberikan gambaran simulasi penerapan standar ISO 200001:2018 Tata Kelola Kapasitas Layanan Teknologi Informasi dengan klausul standarisasi terhadap perusahaan asuransi sosial dan review standarisasi tata kelola kapasitas layanan teknologi informasi sebagai pertimbangan dan usulan kepada perusahaan asuransi sosial.
\end{abstract}

Kata kunci: Tata kelola, kapasitas, teknologi informasi, ISO 20000:1-2018.

\section{PENDAHULUAN}

Perusahaan asuransi sosial merupakan lembaga bergerak di bidang pelayanan publik untuk masyarakat yang mempunyai peranan untuk memitigasi dan mengatasi risiko yang terjadi di masa yang akan datang. Dengan coverage/cakupan semua kalangan masyarakat, maka perusahaan asuransi sosial harus dapat menyediakan pelayanan publik yang mudah untuk digunakan. Untuk dapat memberikan pelayanan yang baik dengan menyediakan informasi yang cepat, akurat, dan mudah, maka perusahaan asuransi sosial membutuhkan layanan teknologi informasi yang handal dan 
terpercaya dalam menyediakan informasi yang dibutuhkan.

Hasil survei APJII (Asosiasi Penyelenggara Jasa Internet Indonesia) dalam Buletin APJII edisi tanggal 33 Januari 2019 memberikan gambaran peningkatan 50\% populasi masyarakat yang sudah terhubung ke jaringan [1]. Kondisi ini memberikan kabar kegembiraan dan juga menyimpan kekhawatiran. Kabar gembira hadir dimana penetrasi internet di Indonesia berada pada jalur yang benar, sedangkan kekhawatiran datang pada pengelolaan kapasitas layanan teknologi informasi seiring dengan meningkatnya pengguna internet. Standarisasi yang ada dalam teknologi informasi yang memberikan arahan dan acuan lebih detil mengenai requirement yang diperlukan untuk implementasi dan improvement side adalah standarisasi ISO (International Organization for Standardization) 20000:1-2018 [2].

Dengan kondisi dimana belum adanya review standarisasi dalam tata kelola layanan teknologi informasi perusahaan asuransi sosial dan belum adanya simulasi penerapan standar ISO 20000:1-2018 pada manajemen kapasitas layanan informasi perusahaan asuransi sosial, maka penelitian ini memberikan jawaban dan gambaran atas review standarisasi dan hasil simulasi standar ISO 20000:1-2018. Penelitian ini diharapkan dapat digunakan sebagai pertimbangan dan usulan bagi organisasi untuk meningkatkan kualitas tata kelola kapasitas layanan teknologi informasi sesuai standar ISO
20000:1-2018, serta memberikan informasi dan pengetahuan sektor publik bahwa tata kelola layanan teknologi informasi sangat penting untuk menjadi perhatian.

Pembahasan mengenai tata kelola kapasitas layanan teknologi informasi dan standarisasinya telah ada dilakukan penelitian sebelumnya. Penelitian-penelitian terdahulu tersebut yaitu Analisis Penerapan Sistem Manajemen Mutu ISO 9001:2015 Dalam Menunjang Pemasaran (Studi pada PT Tritama Bina Karya Malang) [3], Implementasi Manajemen Kapasitas Layanan Dengan Framework IT-IL Dalam Penyusunan Rencana Infrastruktur TI pada Puskom PTS Di Jabar [4], Perancangan Tata Kelola Manajemen Layanan Teknologi Informasi Berdasarkan Standar ISO 20000 di Direktorat Sistem Informasi Universitas Telkom (Studi Kasus: Layanan Human Resources Information System) [5], Building up an IT Service Management System through the ISO 20000 Certification [6], dan Comparison of Models and Standards for Implementing IT Service Capacity Management [7].

Selain penelitian tersebut, referensi yang digunakan dalam penelitian ini sebagian besar bersumber dari standar ISO 20000:1-2018 yang berisikan klausul-klausul yang terdiri dari subsub klausul untuk penguraian aspek penilaian. Kerangka ISO 20000:1-2018 mengenai kapasitas tata kelola layanan teknologi informasi dapat dilihat pada gambar 1 . 


\begin{tabular}{|c|c|c|c|c|c|}
\hline \multirow{7}{*}{$\begin{array}{l}\text { Customers } \\
\text { (Internal \& } \\
\text { External) }\end{array}$} & & \multicolumn{4}{|c|}{ SERVICE MANAGEMENT SYSTEM (SMS) } \\
\hline & & \multicolumn{4}{|c|}{$\begin{array}{l}\text { CONTEXT OF THE ORGANIZATON } \\
\text { - Organization and its Context - Interested Parties - Scope of the SMS - Establish the SMS }\end{array}$} \\
\hline & & \multicolumn{4}{|c|}{$\begin{array}{ll}\text { - Leadership \& Commitment } & \text { LEADERSHIP } \\
\text { Pollicy } \cdot \text { Roles, Re }\end{array}$} \\
\hline & & \multicolumn{4}{|c|}{$\begin{array}{l}\text { PLANNING } \\
\text { - Risks and Opportunities } \cdot \text { Objectives - Plan the SMS }\end{array}$} \\
\hline & & \multicolumn{4}{|c|}{$\begin{array}{c}\text { SUPPORT OF THE SMS } \\
\cdot \text {-Resources } \cdot \text { Competence } \cdot \text { Awareness } \cdot \text { Communication } \cdot \text { Documented Information } \cdot \text { Knowledge }\end{array}$} \\
\hline & & $\begin{array}{l}\text { OPERATIONAL PLANNING \& CONTROC } \\
\text { Service PORTFouo } \\
\text { - Service Delivery } \\
\text { - Plan the Services } \\
\text { - Control of Parties inwolved in the } \\
\text { Service Lifecycle } \\
\text { - Service Catalogue Management } \\
\text { - Asset Management } \\
\text { - Configuration Management }\end{array}$ & $\begin{array}{l}\text { OPERA } \\
\text { ReLAnONSH } \\
\text { - Business } \\
\text { Managem } \\
\text { - Service Le } \\
\text { - Supplier M }\end{array}$ & $\begin{array}{l}\text { OF THE SM: } \\
\text { sREENENT } \\
\text { nship } \\
\text { nagement } \\
\text { ment }\end{array}$ & 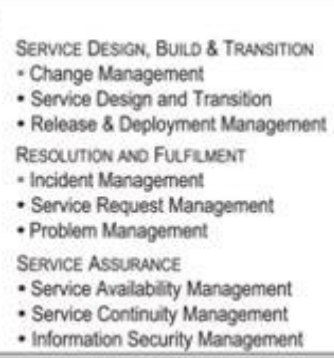 \\
\hline & & $\begin{array}{l}\text { PERFORMANCE EVALU, } \\
\text { - Monitoring, Measurement, Analysis } 8 \\
\text { - Internal Audit } \\
\text { - Management Review } \\
\text { - Service Reporting }\end{array}$ & $\begin{array}{l}\text { MION } \\
\text { Evaluation }\end{array}$ & $\begin{array}{l}\text { - Nonconfo } \\
\text { - Continual }\end{array}$ & $\begin{array}{l}\text { IMPROVEMENT } \\
\text { nity and Corrective Action } \\
\text { mprovement }\end{array}$ \\
\hline
\end{tabular}

\section{Gambar 1. Kerangka ISO 20000:1-2018.[2]}

Dan Klausul serta sub-sub klausul didalamnya

terdapat dalam tabel berikut:

Tabel 1. Klausul dan Sub-klausul Standar ISO 20000:1-2018 Operation of The Service Management System.

\begin{tabular}{c}
\hline Klausul ISO 20000:1-2018 Tata Kelola \\
Kapasitas Layanan Teknologi Informasi \\
\hline Operation of The Service Management System \\
Service Portfolio \\
Configuration Management \\
Relationship and Agreement \\
Service Level Management \\
Supply and Demand \\
Budgeting and Accounting For Services \\
Demand Management \\
Capacity Management \\
Service Design, Build and Transition \\
Change Management \\
Release and Deployment Management \\
Resolution and Fulfilment \\
Service Request Management \\
Problem Management \\
Service Assurance \\
Service Availability Management \\
Service Continuity Management \\
\hline Sumber: https://www.iso.org [2].
\end{tabular}

Tabel 2. Klausul dan Sub-klausul Standar ISO 20000:1-2018 Performance Evaluation.

Klausul ISO 20000:1-2018 Tata Kelola

Kapasitas Layanan Teknologi Informasi

Performance Evaluation

Monitoring, Measurement, Analysis, and Evaluation

Laporan Monitoring dan Evaluasi atas

Layanan TI

Service Reporting

Laporan Kinerja Atas Layanan TI

Sumber: https://www.iso.org [2]

Komponen Operation of The Service Management System meliputi klausul Service Portfolio; Relationship and Agreement; Supply and Demand; Service Design, Build and Transition; Resolution and Fulfilment, dan Service Assurance.

Komponen Performance Evaluation mencakup Monitoring, Measurement, Analysis, and Evaluation dan Service Reporting. 


\section{METODOLOGI PENELITIAN}

Penelitian terhadap tata kelola kapasitas layanan teknologi informasi perusahaan asuransi sosial menggunakan ISO 20000:1-2018 ini memakai pendekatan atau paradigma postpositivisme dengan pengumpulan data kualitatif dan studi literatur.

Pendekatan penelitian tersebut digunakan dengan alasan adalah (1) Adanya interaksi yang erat di antara realitas (objek penelitian), (2) ciri pendekatan post-positivisme mendasarkan pada verifikasi teori dimana penelitian ini mengacu pada acuan teoritis dalam rangka melihat isi dan implementasi tata kelola kapasitas layanan teknologi informasi perusahaan. Pandangan postpositivisme dilakukan untuk mengkaji dan mengidentifikasi faktor-faktor penyebab yang mempengaruhi hasil akhir suatu penelitian [8]. Dalam hal ini, sangat penting bagi peneliti yang menggunakan metode kualitatif untuk memastikan kualitas dari proses penelitian, sebab peneliti akan menginterpretasi data yang telah dikumpulkannya. Tahapan metode penelitian secara umum tergambar pada gambar 2.

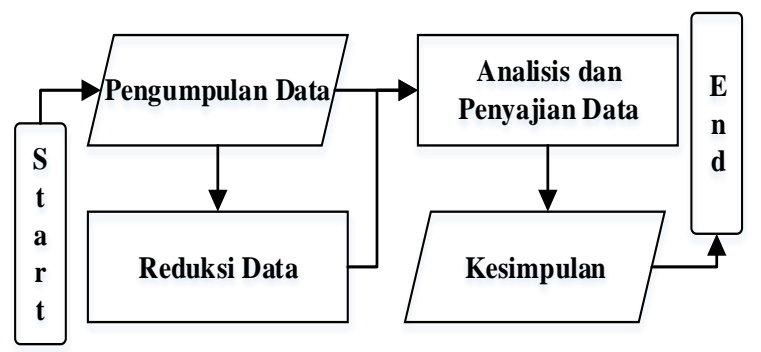

Gambar 2. Tahap Metode Penelitian

Penelitian ini dimulai dengan tahap pengumpulan data dengan menggunakan studi lapangan berupa wawancara semi terstruktur dan studi literatur yang merujuk pada referensi buku, jurnal, sumber ilmiah, serta standar ISO/IEC 20000:1-2018 itu sendiri.

Kemudian lanjut ke tahap berikutnya yaitu melakukan penyaringan data dari hasil pengumpulan data yang didapatkan di tahap awal. Penyaringan/reduksi data dilakukan dengan menggunakan fokus pada data relevan yang dibutuhkan dan mengesampingkan data yang tidak relevan dengan penelitian.

Setelah proses reduksi data dilakukan, didapatkan data yang dapat disajikan dengan kategori dan jenis data yang dibutuhkan dan mendukung penelitian. Penyajian dapat disajikan berupa angka, tabel, gambar/grafik.

Tahap terakhir dalam metode penelitian ini adalah penarikan kesimpulan. Data yang sudah didapatkan disajikan sedemikian rupa untuk mendukung hasil dan kesimpulan yang sudah didapatkan dari pengolahan data yang ada. Kesimpulan didapatkan dari informasi yang berasal dari data yang disajikan, sehingga akan memudahkan bila informasi yang didapatkan detil dan rinci.

\subsection{Pengumpulan Data}

Pengumpulan data dilakukan dengan studi lapangan dan studi literatur. Studi lapangan dilakukan dengan wawancara mendalam (indepht interview) kepada pihak-pihak yang terkait dengan tata kelola kapasitas teknologi informasi di lingkungan perusahaan asuransi social, dan studi literatur yang dilakukan dengan pengecekan dokumen dan proses tata kelola sesuai dengan parameter/indikator yang ada dalam standarisasi tata kelola kapasitas layanan teknologi informasi yang ada. 
Studi lapangan (field research) merupakan suatu metode yang dilakukan dengan cara pengamatan langsung pada objek penelitian [9]. Dalam tahap wawancara, dilakukan dengan sampel populasi sebagai sumber data dalam penelitian ini adalah dilakukan secara purposive lengkap yaitu semua pihak yang dianggap sebagai representative dengan mempertimbangkan relevansi antara pengetahuan dan informasi yang dimiliki informan terhadap topik yang diteliti.

Data studi literatur dalam penelitian ini adalah klausul-klausul beserta sub-sub klausul indikator/parameter yang ada dalam standar ISO 20000:1-2018. Parameter/indikator tersebut digunakan sebagai petunjuk untuk mendeskripsikan dan mendefinisikan kondisi/proses yang sudah ada. Kemudian dari semua parameter/indikator tersebut akan didapatkan gambaran yang akan membantu dalam tahap selanjutnya yaitu melakukan analisis data.

\subsection{Analisis Data}

Sebelum dilakukan analisis data, terlebih dahulu dilakukan reduksi dan kompilasi data sehingga data yang akan dianalisis merupakan data utuh yang dibutuhkan dan relevan. Analisis yang dilakukan dalam penelitian ini dengan membandingkan antara hasil studi literatur dan hasil wawancara yang telah dilakukan (analisis hasil pengumpulan data/kompilasi data), analisis simulasi penerapan standar ISO/IEC 200001:2018 terhadap tata kelola layanan teknologi informasi yang ada di perusahaan asuransi sosial. Penelitian ini menggunakan metode penelitian kualitatif deskriptif dengan rumusan kesimpulan di akhir proses penelitian

Teknis analisis data dalam penelitian ini merujuk pada tahapan proses reduksi data, kemudian dilanjutkan dengan penyajian data, dan terakhir dilakukan verifikasi dan penarikan kesimpulan [10].

\section{HASIL DAN PEMBAHASAN}

Dari parameter dan sub-parameter komponen standar ISO/IEC 20000:1-2018 didapatkan parameter dan sub-parameter komponen yang relevan. Aksi tersebut memberikan petunjuk komponen parameter yang dapat menjadi fokus standar untuk penelitian.

Terdapat dua fokus penerapan dalam sistem manajemen mutu standar ISO/IEC 20000:1-2018 yang disimulasikan, yaitu mengenai operasional dari manajemen sistem layanan teknologi informasi dan evaluasi kinerja kapasitas layanan teknologi informasi.

\subsection{Analisis Simulasi Penerapan ISO 20000:1-2018 Tata Kelola Kapasitas}

\section{Layanan Teknologi Informasi}

Untuk fokus penerapan Manajemen Sistem Layanan Teknologi Informasi yang ada pada standar ISO/IEC 20000:1-2018 meliputi 6 klausul dan 11 sub-klausul yang harus terpenuhi. Untuk fokus penerapan Evaluasi Kinerja Kapasitas Layanan Teknologi Informasi meliputi 2 klausul dan 2 sub klausul yang harus terpenuhi. 


\subsubsection{Manajemen Sistem Layanan Teknologi Informasi}

Hasil penelitian atas penerapan fokus Manajemen Sistem Layanan Teknologi Informasi ISO 20000:1-2018 pada perusahaan asuransi sosial sebagai berikut:

\section{Service Portofolio}

Dalam klausul ini berfokus pada manajemen konfigurasi yang berupa proses sistem yang ada di perusahaan asuransi sosial untuk menetapkan dan mempertahankan konsistensi kinerja, fungsional, dan atribut fisik suatu produk layanan dengan persyaratan, desain, dan informasi operasionalnya. Manajemen konfigurasi perusahaan sosial didefinisikan sebagai model domain untuk dapat mengelola perubahan dan kebutuhan perusahaan asuransi sosial.

Perusahaan asuransi sosial sendiri sudah memiliki model Configuration Management Database untuk menyesuaikan perubahan dan melakukan pengelolaa sesuai dengan kebutuhan perusahaan dan permintaan dari manajemen. Selain itu lebih detilnya, perusahaan asuransi sosial sudah memiliki dokumen dan standar prosedur yang berisikan definisi dari masingmasin tipe Configuration Item (CI), dimana informasi yang terekan terkait CI sudah meliputi deksripsi CI, relasi CI, dan status CI. Sehingga dengan manajemen konfigurasi yang sudah ada, perusahaan asuransi sosial tidak perlu takut dalam melakukan penyesuaian kapasitas layanan teknologi informasi.

\section{Relationship and Agreement}

Klausul relationship and agreement meliputi service level management yang berinti pada menentukan service level agreement (SLA). Hal ini berarti fokus klausul ini adalah menentukan parameter-parameter agar layanan bisa dikatakan lancar berjalan. Sehingga dengan kata lain klausul ini melihat tingkat layanan yang dapat mempengaruhi sudut pandang customer perusahaan asuransi sosial.

Perusahaan asuransi sosial belum memadai dalam klausul service level management dari standar ISO/IEC 20000-1:2018 karena perusahaan asuransi sosial masih kurang dalam hal dokumen pakta integritas/perjanjian operasional layanan, persetujuan dokumen SLA oleh pelanggan, dan belum ada pemantauan atas kinerja terhadap target kinerja layanan seti

\section{Supply and Demand}

Hasil penelitian memotret proses pemenuhan manajemen kapasitas layanan teknologi informasi dari database, jumlah user, loading transaction, dan lainnya sudah berjalan beriringan dengan visi perusahaan asuransi sosial karena sudah diakomodasi dengan capacity plan yang ada dalam capacity management.

Perusahaan asuransi sosial masih belum memenuhi standar pada klausul supply and demand pada ISO/IEC 20000-1:2018 karena belum adanya kebijakan mengenai sumber daya manusia (tenaga kerja) terkait pengalokasian tenaga kerja, penyediaan kebutuhan tenaga kerja, jenjang kompetensi dan lainnya, serta hal ini belum dimasukkan dalam rencana kerja dan anggaran tahunan dari perusahaan asuransi sosial 
sehingga akan sulit untuk memenuhi beban kerja, kebutuhan permintaan layanan teknologi informasi dari tingkat teknis sampai ke tingkat manajemen.

\section{Service Design, Build, and Transition}

Perusahaan asuransi sosial dalam memenuhi klausul change management pada standar ISO/IEC 20000-1:2018 karena perusahaan asuransi masih lemah dan mempunyai beberapa kekurangan dalam hal prosedur penjadwalan perubahan dan deploy, perencanaan dan testing untuk change yang tidak sukses, rekaman change management database yang sudah ter-update sesuai dengan deployment of change, review secara berkala dalam memastikan efektivitas dan pengambilan keputusan/langkah dengan pihak terkait, serta analisis tren terkait dengan request for change (RFC).

\section{Resolution and Fulfilment}

Perusahaan asuransi sosial menyediakan penanganan kendala dan hambatan berupa helpdesk. Dan untuk penanganan tingkat darurat/urgent sudah dibuat standar operasi penanganan oleh tim operasional teknologi informasi beserta kebijakan tindakan dalam penanganan kondisi tersebut.

Terkait klausul problem management, di perusahaan asuransi sosial sudah ada prosedur dan SOP (Standar Operasi Prosedur) untuk manajemen masalah seputar kapasitas layanan teknologi informasi. Poin yang telah dipenuhi yaitu prosedur identifikasi masalah, rekaman dan update atas masalah yang terjadi, alokasi prioritas penyelesaian/penanganan masalah, klasifikasi masalah, eskalasi masalah, resolusi atas masalah, dan penutupan masalah.

Dengan adanya prosedur penanganan masalah kapasitas layanan teknologi informasi ini, perusahaan asuransi sosial sudah memenuhi kriteria standar ISO/IEC 20000-1:2018 mengenai manajemen masalah.

\section{Service Assurance}

Pada bagian perencanaan continuity dan availability management, perusahaan asuransi sosial sudah ada perencanaan terkait keberlangsungan layanan teknologi informasi yang mencakup prosedur antisipasi kerugian yang besar, target ketersediaan dan rencana pemenuhan, pemulihan, mekanisme pengembalian kondisi normal, dan ketersediaan yang diminta (availability request) dan yang ditargetkan.

Pada bagian requirement, perusahaan asuransi sosial sudah menyediakan laporan Business Impact Analysis (BIA) yang dilakukan atas layanan dan dikonfirmasi dengan pihak pengguna/pelanggan, dan pemenuhan atas dokumen kualitas ketersediaan dan keberlangsungan layanan yang mencakup hak akses layanan, waktu tanggap layanan, dan ketersediaan hulu-hilir layanan teknologi informasi.

\subsubsection{Evaluasi Kinerja Kapasitas Layanan Teknologi Informasi}

Hasil penelitian atas penerapan fokus Evaluasi Kinerja Kapasitas Layanan Teknologi 
Informasi ISO 20000:1-2018 pada perusahaan asuransi sosial sebagai berikut:

1. Monitoring dan evaluasi atas layanan teknologi informasi

Perusahaan asuransi sosial sudah mempunyai kepedulian dalam hal monitoring progress atas layanan teknologi informasi yang dilakukan setiap triwulan, akan tetapi monitoring tersebut belum sampai pada tingkat evaluasi untuk dilakukan pembenahan dan pengembangan lebih lanjut sesuai dengan kebutuhan perusahaan dan manajemen. Tahap evaluasi yang dilakukan dalam perusahaan asuransi sosial belum sampai pada tingkat kebijakan manajemen sehingga tidak dapat dilakukan tindak lanjut langsung atas hasil monitoring evaluasi yang telah dilakukan.

\section{Pelaporan kinerja atas layanan teknologi informasi}

Pelaporan kinerja yang telah ada, belum dapat memberikan informasi yang dibutuhkan dalam membuat rancangan, evaluasi, serta peningkatan akan kapasitas layanan teknologi informasi perusahaan asuransi sosial. Keterbatasan sumber daya manusia dan tidak jelasnya prosedur pelaporan dan kebijakan mengakibatkan menurunnya tingkat kepedulian terhadap administrasi pelaporan kinerja layanan teknologi informasi.

\subsection{Gap Pada Perusahaan Asuransi Sosial}

\section{Menggunakan Klausul ISO 20000:1-2018}

Hasil dari analisis data yang sudah dikumpulkan dengan merujuk pada klausulklausul yang ada pada standar ISO/IEC 20000:12018, didapatkan hasil seperti pada tabel 3 dan 4 .
Tabel 3. Hasil Analisis Data Menggunakan Klausul Standar ISO 20000:1-2018 Operation of The Service Management System

\begin{tabular}{|c|c|}
\hline $\begin{array}{c}\text { Klausul ISO 20000:1-2018 Tata } \\
\text { Kelola Kapasitas Layanan } \\
\text { Teknologi Informasi }\end{array}$ & Progress \\
\hline \multicolumn{2}{|c|}{ Operation of The Service Management System } \\
\hline \multicolumn{2}{|l|}{ Service Portfolio } \\
\hline Configuration management & terpenuhi \\
\hline \multicolumn{2}{|l|}{ Relationship and Agreement } \\
\hline Service level management & on progress \\
\hline \multicolumn{2}{|l|}{ Supply and Demand } \\
\hline $\begin{array}{l}\text { Budgeting and accounting for } \\
\text { services }\end{array}$ & on progress \\
\hline Demand management & on progress \\
\hline Capacity management & terpenuhi \\
\hline \multicolumn{2}{|l|}{$\begin{array}{l}\text { Service Design, Build and } \\
\text { Transition }\end{array}$} \\
\hline $\begin{array}{l}\text { Change management } \\
\text { Release and deployment } \\
\text { management }\end{array}$ & $\begin{array}{l}\text { on progress } \\
\text { on progress }\end{array}$ \\
\hline \multicolumn{2}{|l|}{ Resolution and Fulfilment } \\
\hline $\begin{array}{l}\text { Service request management } \\
\text { Problem management }\end{array}$ & $\begin{array}{l}\text { terpenuhi } \\
\text { terpenuhi }\end{array}$ \\
\hline \multicolumn{2}{|l|}{ Service Assurance } \\
\hline $\begin{array}{l}\text { Service availability management } \\
\text { Service continuity management }\end{array}$ & $\begin{array}{l}\text { terpenuhi } \\
\text { terpenuhi }\end{array}$ \\
\hline
\end{tabular}

Tabel 4. Hasil Analisis Data Menggunakan Klausul Standar ISO 20000:1-2018 Performance Evaluation

\begin{tabular}{ll}
\hline $\begin{array}{c}\text { Klausul ISO 20000:1-2018 Tata } \\
\text { Kelola Kapasitas Layanan } \\
\text { Teknologi Informasi }\end{array}$ & Progress \\
\hline \multicolumn{1}{c}{ Performance Evaluation } \\
$\begin{array}{l}\text { Monitoring, Measurement, } \\
\text { Analysis, and Evaluation } \\
\text { Laporan monitoring dan }\end{array}$ \\
$\begin{array}{l}\text { evaluasi atas layanan TI } \\
\text { Service Reporting }\end{array}$ \\
$\begin{array}{l}\text { Laporan kinerja atas layanan progress } \\
\text { TI } \quad \text { on progress }\end{array}$ \\
\hline
\end{tabular}

\subsection{Hambatan Pemenuhan Standar ISO} 20000:1-2018 Tata Kelola Layanan Teknologi Informasi

Beberapa hambatan dialami oleh perusahaan asuransi sosial dalam memenuhi standar ISO/IEC 20000:1-2018 terkait tata kelola 
kapasitas layanan teknologi informasi, hambatan-hambatan ini diantaranya:

1. Struktur organisasi sudah jelas dan memadai, akan tetapi masih terlalu banyak loading pekerjaan dalam unit teknologi informasi sehingga fokus pekerjaan karyawan terganggu. Hal ini dinyatakan dalam hasil wawancara pada hari Selasa tanggal 21 Mei dan tanggal 25 Juni tahun 2019, hari Rabu tanggal 22 Mei dan 26 Juni tahun 2019; dimana dari 5 korespondensi, 4 koresponden menyatakan bahwa beban loading pekerjaan yang tidak sesuai dengan jumlah sumber daya manusia yang tersedia.

2. Prosedur dan kebijakan operasional teknologi informasi perusahaan asuransi sosial yang belum memadai dan rinci.

3. Kurangnya pengetahuan karyawan mengenai perkembangan teknologi informasi dan standarisasi tata kelola.

Hambatan ini dinyatakan dalam hasil wawancara pada tanggal $21 \mathrm{Mei}$, tanggal 22 Mei, tanggal 25 Juni, dan tanggal 26 Juni tahun 2019; dimana dari 5 korespondensi, 3 koresponden menyatakan bahwa perusahaan asuransi sosial belum aktif dalam mengikuti seminar dan workshop terkait standarisasi dan perkembangan teknologi informasi

4. Sumber daya manusia yang terbatas.

5. Karyawan tidak menjalankan prosedur dan kebijakan dengan konsisten. Hal ini dinyatakan dalam hasil wawancara pada tanggal $21 \mathrm{Mei}$, tanggal $22 \mathrm{Mei}$, tanggal 25 Juni, dan tanggal 26 Juni tahun 2019; dimana dari 5 korespondensi, 3 koresponden menyatakan bahwa dikarenakan beban loading pekerjaan dan kurangnya sumber daya manusia sehingga menyebabkan monitoring dan evaluasi belum berjalan secara periodik sesuai dengan kebijakan yang berlaku.

Hambatan - hambatan ini dapat memberikan dampak kerugian perusahaan asuransi sosial bila sering diabaikan. Oleh karena itu, perusahaan asuransi sosial perlu membuat perencanaan, perancangan, standarisasi, pengendalian, mitigasi risiko, dan peningkatan kualitas yang berkelanjutan sehingga hambatan dan masalah yang ada dapat dikelola dan dicegah/dimitigasi.

\section{KESIMPULAN}

Kegiatan analisis tata kelola kapasitas layanan teknologi informasi perusahan asuransi sosial ini dimulai dengan melakukan pengumpulan data primer dan data sekunder. Dari penyajian informasi yang bersumber pada data primer dan data sekunder tersebut diidentitikasi bahwa perusahaan asuransi sosial sudah mempunyai dan menerapkan best practice berupa prosedur dan kebijakan internal perusahaan untuk tata kelola kapasitas layanan teknologi informasi. Namun masih ditemukan gap dan celah yang harus dibenahi dan dijadikan sebagai area improvement bagi perusahaaan asuransi.

Adapun gap area dan sub-klausul yang belum memenuhi standar ISO/IEC 20000:1-2018 ditemukan dalam hasil kegiatan analisis data penelitian ini sebagai berikut:

1. Service level management,

2. Budgeting and accounting for services, 
3. Demand management,

4. Change management,

5. Release and deployment management,

6. Laporan monitoring dan evaluasi atas layanan teknologi informasi,

7. Laporan kinerja atas layanan teknologi informasi.

Sedangkan untuk sub-klausul yang sudah memenuhi standar ISO/IEC 20000:1-2018 ditemukan dalam hasil kegiatan analisis data penelitian ini sebagai berikut:

1. Configuration management,

2. Capacity management,

3. Service request management,

4. Problem management,

5. Service availability management,

6. Service continuity management.

Dengan masih banyaknya gap area tata kelola kapasitas layanan teknologi informasi perusahaan asuransi sosial yang masih belum memenuhi standar ISO/IEC 20000:1-2018, maka akan terjadi tingkat kerentanan dan risiko yang cukup tinggi bagi perusahaan asuransi sosial dalam memberikan dan memastikan kecukupan dan keberlangsungan tata kelola kapasitas layanan teknologi informasi yang dimiliki. Sehingga perlu dilakukan perbaikan dan peningkatan pada gap area tersebut sesuai dengan standar ISO/IEC 20000:1-2018 secara berkelanjutan dan konsisten oleh perusahaan asuransi sosial.

\section{DAFTAR PUSTAKA}

[1] Buletin APJII. BULETIN APJII EDISI 35 Maret 2019. [Online]. Avaiable: https://apjii.or.id/content/read/104/402/BUL ETIN-APJII-EDISI-35--Maret-2019 [Accessed: 01-Mar-2019].

[2] ISO. ISO/IEC 20000-1:2018. Avaiable:https://www.iso.org/standard/7063 6.html [Accessed: 18-Mar-2019].

[3] Ramadhany, Fitriana Fajrin,\& Supriono. Analisis Penerapan Sistem Manajemen Mutu ISO 9001:2015 Dalam Menunjang Pemasaran (Studi pada PT Tritama Bina Karya Malang), Jurnal Administrasi Bisnis Universitas Brawijaya, vol.53(01), pp.3138, 2017.

[4] Tasli, Endang. Implementasi Manajemen Kapasitas Layanan Dengan Framework ITIL Dalam Penyusunan Rencana Infrastruktur TI pada Puskom PTS Di Jabar. [Online]. Avaiable at: http://jurnal.lpkia.ac.id/index.php/jkb/article /view/117 [Accessed: 11-Jul-2019].

[5] Saputro, Toni. Perancangan Tata Kelola Manajemen Layanan Teknologi Informasi Berdasarkan Standar ISO 20000 di Direktorat Sistem Informasi Universitas Telkom (Studi Kasus: Layanan Human Resources Information System). [Online]. Avaiable:https://openlibrary.telkomuniversit y.ac.id/pustaka/134653/perancangan-tatakelola-manajemen-layanan-teknologiinformasi-berdasarkan-standar-iso-20000di-direktorat-sistem-informasi-universitastelkom-studi-kasus-layanan-humanresources-management-information-system.html [Accessed: 18-Jul-2019].

[6] Hoon, Park Jung. Kim Hwan Min. Building up an IT Service Management System through the ISO 20000 Certification. [Online]. Avaiable: https://www.researchgate.net/publication/27 1257491_Building_up_an_IT_Service_Man agement_System_through_the_ISO_20000_ Certification [Accessed: 11-Jul-2019].

[7] Sanchez, Alleinni Feliz. Jose Antonio Calvo Manzano. Comparison of Models and Standards for Implementing IT Service Capacity Management. Avaiable: https://www.researchgate.net/publication/28 3094642_Comparison_of_models_and_stan dards_for_implementing_IT_service_capaci ty_management [Accessed: 19-Jul-2019]. 
[8] Moleong, Lexy J. Metodologi Penelitian Kualitatif. Bandung : PT Remaja Rosdakarya, 2012.

[9] Creswell W. John. 2013. Research Design Pendekatan Kualitatif, Kuantitatif, dan Mixed. Yogyakarta : Pustaka Pelajar.

[10] Neuman, W. Laurence. 2014. Social Research Methods: Qualitative and Quantitative Approaches .New York: Pearson. 